\title{
Ubuntu: uma filosofia alternativa à crise ambiental
}

\section{Ubuntu: an alternative philosophy to the environmental crisis}

\author{
iD Carlos Frederico Mares De Souza Filho ${ }^{1}$
}

(iD) Nicolle Sayuri Uyetaque ${ }^{2}$

iD) Hermelindo Chico ${ }^{3}$

Data de submissão do artigo: Março de 2021

Data de aceite do artigo: Novembro de 2021

\begin{abstract}
1 Possui graduação em Direito pela Universidade Federal do Paraná (1969), mestrado em Direito pela Universidade Federal do Paraná (1988 - Proteção Jurídica dos Bens Culturais) e doutorado em Direito pela Universidade Federal do Paraná (1998 - Direito dos Povos Indígenas) Integra o Programa de Mestrado e Doutorado da Pontifícia Universidade Católica do Paraná, onde é professor titular de Direito Agrário e Socioambiental. É líder do Grupo de Pesquisa "Meio Ambiente: sociedades tradicionais e sociedade hegemônica" certificada pelo CNPq e pela PUCPR. Foi procurador do Estado do Paraná de 1981 a 2015. Foi Secretário de Cultura de Curitiba e Presidente da Fundação Cultural de Curitiba, Procurador Geral do Estado do Paraná, Presidente da FUNAI (Fundação Nacional do Índio), Procurador Geral do INCRA (Instituto Nacional de Colonização e Reforma Agrária), Diretor do Banco Regional de Desenvolvimento do Extremo Sul, do qual foi presidente, foi membro do Conselho do Patrimônio Histórico e Artístico do Paraná de 2003 a 2010. Foi novamente Procurador Geral do Estado do Paraná em 2008-2009.

2 Sócia fundadora e CEO da Startup Ybyram Gamificação Sustentável Ltda. Mestranda e bolsista Capes no Programa de Pós-graduação em Direito, na área de Direito Socioambiental e Sustentabilidade, com tema de pesquisa: Sustentabilidade em cidades brasileiras, da PUCPR. Advogada Consultora em Sustentabilidade, pós-graduada em Direito Ambiental, pela PUCPR, onde também graduou-se em Direito. Membro do Grupo de Pesquisa “Meio Ambiente: Sociedades Tradicionais e Sociedade Hegemônica", vinculado ao PPGD da PUCPR e ao CNPq. Membro do Conselho do Instituto Brasileiro de Admnistração do Sistema Judiciário - IBRAJUS.
\end{abstract}

3 Possui graduação em Administração Pública pela Universidade da Integração Internacional da Lusofonia Afro-Brasileira (2018). Mestre em Direito Socioambiental e Sustentabilidade na Pontifícia Universidade Católica do Paraná-PUCPR (2020). 


\section{Introdução}

Ubuntu4 é a filosofia africana do equilíbrio. Para analisar a relação humana com a natureza, é necessário abordar pelo menos questões: propriedade, exploração, mercado, trabalho e riscos. O processo em que se deu a modernidade foi degradante para África e América Latina porque separou a humanidade da natureza e desconsiderou a cultura e filosofia e conhecimento dos povos tradicionais e indígenas.

O processo histórico da modernidade tem nos mostrado a sinistra relação do ser humano com a natureza. Esta relação é acompanhada por várias transformações, mudanças e evolução social, que resultou, gradativamente, numa crise com a própria natureza. O processo de apropriação e cerceamento das terras foi uma alavanca para a comercialização do solo. A modernidade capitalista, então, enxergou a natureza apenas como objeto e propriedade para a sua exploração a fim de produzir lucro. Deste modo, a humanidade vem destruindo a natureza e, consequentemente, colocando o próprio ambiente em risco.

O mundo globalizado atual quase tudo se torna possível (Morin; Kern, 2003, p. 21). A globalização unifica as nações e as separa na mesma proporção, ou seja, torna próximo e distante uns dos outros. A globalização é um feito do sistema de produção capitalista colonial. A grande dificuldade desta nova ordem (capitalista global) é a crescente desigualdade social que tem originado fome, pobreza, miséria, guerra. Dessa maneira, o capitalismo representa uma base da sociedade de risco (Beck, 2012, p. 11-15). Nações outrora consideradas ricas e bem organizadas foram destruídas pelo sistema de produção capitalista colonial, quem sabe as duas maiores vítimas tenham sido justamente a África, antes muito bem estruturada em seus reinos e povos plenos de natureza rica e a América. Embora ambas as regiões continuem sendo a

$\overline{4 \text { Ubuntu é um termo }}$ da linguagem banta dos povos Bantu (africanos). A expressão é encontrada nas línguas Nguni dos Zulus, Xhosa ou Ndebele. Existe um conceito similar nas línguas Sotho-Tswana derivado da expressão proverbial ‘Motho ke motho ka batho babang'(não existe tradução para a Língua Portuguesa), assim como em outras línguas derivadas do Bantu. 
maior fonte alternativa de riqueza para as potências capitalistas, a África é hoje um continente devastado pela miséria, fome, guerra e doenças promovidas pelos colonizadores europeus, desde a época das grandes navegações até a contemporaneidade.

Tais problemas tornaram-se possível com o surgimento da era moderna, conforme nos ensinam Edgar Morin e Anne Kern (2003). Desde a revolução da era moderna até a contemporaneidade, o ser humano tem se tornado um grande predador da natureza e da sua própria espécie. Por isso, nas últimas décadas tem se discutido a respeito da crise da modernidade em vários fóruns. O debate atual tem demonstrado que a crise deriva dos problemas ecológicos e ambientais resultantes da apropriação e exploração humana na natureza. Assim sendo, o mundo global é caracterizado pela constante crise ambiental, além da complexidade dos problemas ecológicos. A proteção ao meio ambiente torna-se um dos grandes desafios da era moderna. Para garantir que a natureza sobreviva e, com isso, a espécie humana, a principal obrigação do Estado de Direito é a proteção, incentivando de alguma forma a sociedade na preservação da natureza e o meio ambiente. Por esse motivo, toda prática de caráter sustentável merece a nossa atenção. Começa um processo de retorno à vida tradicional buscando a agricultura compatível com a natureza em terras antes ocupadas por agricultura industrial, como o caso de Zimbabwe onde "por meio de sua ação e uso de conhecimento local, os migrantes nativos têm conseguido reagir aos desafios aumentando culturas resilientes às condições climáticas variáveis de modo bem-sucedido" (Le Grange, 2015, p. 4-5).

No cultivo de plantios tradicionais, o conhecimento prévio e os recursos para semeadura que os membros da comunidade trouxeram com eles foram mobilizados para construir a capacidade da comunidade local de suportar mudança ambiental. Este conhecimento local era, portanto, recuperado e sustentado dentro das comunidades locais. Por exemplo, a Sra. Mberengwa [migrante nativa] lembrou como no passado, no seu local de residência 
original, Gutu, onde havia seca, eles desenvolveriam a cultura de cereais resistentes à seca (Shavah et al, 2009, p. 225).

Esta é uma evidência de que o conhecimento tradicional pode ser uma resposta ou alternativa aos problemas enfrentados pela modernidade. São povos que por vários séculos usam suas práticas e saberes para dar continuidade e existência a seus povos, tribos, grupos, clãs e comunidades. Praticam o bem viver em harmonia com a natureza, porque entendem que o mundo é a natureza e os seres que nela habitam. A cultura africana ensina que a construção da sociedade não deve ser com base na acumulação constante e desproporcional dos bens matérias, nem orientada no sentido da apropriação agressiva da natureza. É nesse contexto que se evidencia a importância de estudar a doutrina tradicional africana Ubuntu como uma filosofia alternativa aos problemas da modernidade, especialmente ecológicos e ambientais.

\section{A Essência Ubuntu}

Desde os primórdios da humanidade que o continente berço manifesta-se de forma espiritual e oral. África é caracterizada pela espiritualidade e oralidade. Todas as ciências foram criadas pela observação da natureza e da espiritualidade. O pilar da medicina tradicional é a espiritualidade, pois a manipulação de ervas para a cura de certas doenças requer um conhecimento espiritual, denominado pelo povo africano como ciência espiritual africana. Uma das primeiras grandes civilizações do mundo (Kemet, Egito) foi construída com base na espiritualidade de Maat (Deusa da verdade, justiça, ordem divina, harmonia, equilíbrio, prosperidade e da reciprocidade). Maat foi uma força espiritual e imutável que fazia com que os egípcios acreditassem que ela regia os fenômenos da natureza. Tudo se constrói através de Maat, “Deusa responsável por toda ordem social e cósmica" (Mota, 2010, p. 3).

O continente africano se exprime de forma oral e espiritual. África não é totalmente carnal, pois tudo que se apresenta na di- 
mensão física apresenta-se na dimensão metafísica, e tudo que se encontra na dimensão pronunciável encontra-se na dimensão não pronunciável. Em África, a espiritualidade é a base para a manifestação das tradições e costumes, estes que sustentam a compreensão do cosmo dentro de uma equação fundamentada na ordem, harmonia e equilíbrio. Assim, em África, as revelações são dadas espiritualmente e inexplicáveis de forma escrita, uma vez que se trata dos ancestrais e sacerdotes da ordem metafísica que transmitem toda informação para a comunidade. Para os povos africanos, o conhecimento é uma inspiração que vem diretamente do espirito, designado por Nzambi ${ }^{5}$ (ou unkulunkulu para o povo zulu da África do Sul, Maat para o povo de Kemet, Olodumare na tradição ioruba da Nigéria, etc.), para transmitir toda informação e sabedoria aos anciões ou sábios, detentores dos princípios e tradições filosóficas (Kaphagawani; Malherbe, 2002, p. 13-14) para que estes liderem mediante Ubuntu e outras doutrinas tradicionais que se propagam no amor.

De acordo com Chico e Uyetaqui (2019), por intermédio da espiritualidade, as comunidades e sociedades africana são arquitetadas e sustentadas pelos pilares da irmandade, respeito, igualdade, solidariedade e fraternidade, estes que estruturam e integram a base e o fundamento de Ubuntu. Embora a palavra não tenha uma tradução exata em outros idiomas, para a língua portuguesa, o termo Ubuntu significaria união, harmonia, todos por todos, "eu sou porque tu és e nós somos porque eles são" (2019, p. 244-246). Quando as pessoas estão ligadas pelo espírito fomentam a humanização e são afetadas pela dor e opressão dos seus próximos, isto é, as pessoas dependem umas das outras para a existência e continuidade da humanidade. Portanto, uma pessoa nutrida ou revestida pelos pilares que formam a essência Ubuntu, é abalada pelo sofrimento do outro, humano ou não, pela devastação florestal, pela guerra, miséria, fome, sofrimento dos animais, etc. A espiritualidade se conecta com todos os seres/elementos (pessoas, animais, plantas, árvores, insetos, entre outros) que juntos

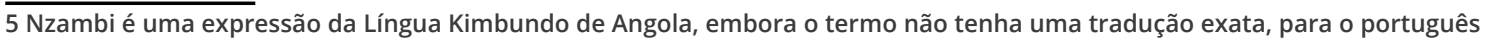
significaria Deus todo-poderoso. O Kimbundo faz parte da grande família de línguas africanas Bantu. 
formam a natureza. A natureza implica enternecimento, sensibilidade, compaixão, respeito e empatia (Chico e Uyetaqui, 2019).

Na concepção Ubuntu, a nossa meta é mantermos o equilíbrio para chegarmos à completude e unidade enquanto seres coletivos, pautados pelo respeito básico da diversidade natural, cultural e da particularidade dos outros ${ }^{6}$. Podemos assim dizer que, Ubuntu é uma filosofia basilar que origina a comunidade (união e espiritualidade) contrária à ideia de sociedade que defende o individualismo para incentivar a competividade entre as pessoas. Enquanto a comunidade promove a coletividade e o bem-estar entre as pessoas em harmonia e equilíbrio com a natureza, o oposto acontece com a sociedade moderna que estabelece um contrato entre as pessoas com caráter de individualidade e segregação. Por isso, a chamada sociedade moderna se caracteriza pela violência. Se para a comunidade o princípio é união, harmonia e todos por todos, na sociedade hegemônica a ordem é cada um por si e todos contra todos (concorrência).

"A filosofia Ubuntu proclama que a realidade e vivência dos seres vivos e não só, estão interconectadas, desta maneira, a condição humana é uma existência coletiva" (Chico e Uyetaqui, 2019245). Por isso, as representações de matriz africanas estão sempre estruturadas em formato de grupos, círculos ou rodas de convivência. Algumas práticas como as rodas de candomblé, rodas de danças tradicionais, rodas de contos de histórias, rodas de capoeira, rodas de semba7, rodas de samba, rodas de adivinha etc., são exemplos desta tradição africana. Neste sentido, Ubuntu é uma filosofia de vida africana, coletiva, comunal.

6 Na filosofia Ubuntu, segundo Chico e Uyetaqui (2019), o outro não se limita a designação de uma pessoa ou simplesmente do ser humano. Assim sendo, o outro poder ser um animal, uma planta, árvore, montanha, estátua ou espirito, etc.

7 Semba é um género musical de Angola, que surgiu nos anos 50 e 60. Etimologicamente, Semba significa "batucada" em Kimbundo, língua de Angola, no entanto, tem vários outros significados adjacentes, como batuque e dança de roda. 


\section{Ubuntu Como Filosofia}

A prática Ubuntu, como doutrina tradicional africana dos povos Bantu ${ }^{8}$, é uma filosofia que busca entender a coletividade de um modo mais integral e humanitária para o alcance do equilíbrio com a natureza. Também se pode dizer que Ubuntu é uma filosofia de vida que nutre o conceito de humanidade, manifestando-se na forma de viver e existir como africano, assim o descreve o filósofo sul-africano Magobe Ramose:

Ubuntu é a raiz da filosofia africana. A existência do africano no universo é inseparavelmente ancorada sobre Ubuntu. Semelhantemente, a árvore de conhecimento africano deriva do Ubuntu com o qual é conectado indivisivelmente. Ubuntu é, então, como uma fonte fluindo ontologia e epistemologia africana. Se estas últimas forem às bases da filosofia, então a filosofia africana pode ser estabelecida em e através do Ubuntu (Ramose, 1999, p. 1).

Partindo dessa concepção, Ubuntu pode ser visto como uma doutrina filosófica basilar africana. Isto é, uma cosmovisão que abraça a África como um todo, doutrinado pelos povos Bantu. A maior parte da população africana é de origem Bantu, que substituíram há 22 mil anos o grupo anteriormente predominante, os khoisan ${ }^{9}$, que ainda hoje vivem em pequenos bolsões, em Angola, Namíbia, Botswana, África do Sul, Lesoto, Suazilândia, Zimbabwe e Moçambique.

Ramose explica que o termo Ubuntu é formado por duas palavras ubu e ntu, que poderia ser grafada com hífen ubu-ntu. Ubu evoca a ideia de existência e $n t u$ é a permanente troca do universo em movimento. Os termos "são dois aspectos da existência como

\footnotetext{
8 Os Bantus formam um grupo étnico africano que habitam a região da África ao sul do Deserto do Saara. A maioria dos mais de 600 subgrupos étnicos é formada por agricultores, que vivem também da pesca e da caça. Estes subgrupos possuem em comum a família linguística banta.

9 Khoisan é a junção de dois grupos, os Khoi e San, conhecidos também como Bosquímanos ou Hotentotes. São descendentes de povos nômades que habitavam a África e foram deslocados com a ocupação dos Bantu. A origem dos Bosquímanos é mitológica e misteriosa: até hoje não há um consenso entre os antropólogos sobre a verdadeira origem deste povo. Alguns historiadores afirmam que os Bosquímanos têm a sua filiação genética a povos asiáticos.
} 
uma unicidade e inteireza indivisível". Portanto, ubu-ntu é uma categoria ontológica e epistemológica no pensamento africano do povo de língua banta (Ramose, 1999, p. 2).

Ubuntu é uma exteriorização perceptível, visível e específica do ubu, um caminhar do geral para o específico concreto de ntu. Ubuntu como doutrina filosófica específica, ocupa-se a dirigir uma diligência ou perscrutação ao ser, saber, vivência e verdade. Ubu é uma fase ou processo, ou seja, quer dizer tornar ou vir a ser. Já o ntu é a forma material ou modo de ser.

Ubuntu vincula-se epistemologicamente a Umuntu. Umuntu significa a emergência do homo loquens, que é simultaneamente um homo sapiens, que significa o ser humano: o criador de política, religião e lei. Umuntu então é uma manifestação concreta e específica do umu: é um caminhar do geral para o específico concreto. Umuntu é uma entidade específica que estende-se a conduzir uma investigação ao ser, experiência, conhecimento e verdade. Esta é uma atividade anterior ao ato. É um processo contínuo impossível de parar (Ramose, 1999, p. 2).

Entretanto, Ubuntu é preconizado como uma categoria ou padrão fundamental da filosofia. Para além do Ubuntu e Umuntu ou muntu, existem outras doutrinas filosóficas de origem africana que se compaginam no amor, por exemplo, Kintu, Hantu e Kuntu, etc. Todas são munidas e ligadas pela espiritualidade e oralidade, fazendo uma analogia sobre a necessidade do equilíbrio ecológico e da união entre as comunidades, ou seja, àquilo que é a ideia de nós existirmos por intermédio dos outros. O elemento fundamental dessas narrativas filosóficas é que nós dependemos uns dos outros para atingirmos a plenitude.

Em África, o universo físico e metafisico são emparelhados em quatro variedades linguísticas, nomeadamente: Muntu, Kintu, Hantu e Kuntu. Essas classificações definem a existência do mundo na cosmovisão africana. Esta quatro categorias estão explicadas pelo filósofo ruandês Alixis Kagame: 
Estas quatro categorias básicas de tudo que existe é bem explicita nas línguas Bantu e podem ser nomeadas como: Muntu, para os seres humanos completos, Kintu, para as coisas animadas e inanimadas consideradas todas como portadores de vida, Han$t u$, representando tudo que tem relação com tempo e espaço, Kuntu, como modalidade ou como os atributos de inter-relação de categorias, como uma força que permite a ligação entre dois significados (Kagame, 1956, p. 449-454).

As expressões Mantu, Kintu, Hantu e Kuntu, assim como a própria palavra Ubuntu, além dos outros termos citados (Nzambi, unkulunkulu, Olodumare) não podem ser interpretados ou traduzidos de forma exata. Uma tradução ou interpretação literal implicaria uma refusão ou rejeição do evidente, do visível e do perceptível, e perderia totalmente a essência significativa da verdadeira palavra. A esse respeito, Ramose (1999) explica que uma interpretação literal dos termos citados, especialmente ubu-ntu, resume a afirmação ou a negação do óbvio e nos restringimos a uma definição moderna de ser humano e de mundo. Portanto, se trata de termos ou expressões que fornecem conhecimentos registrados no código genético do povo africano, e para que seja compreendido devemos nos conectar de forma espiritual para que tais conhecimentos possam emergir as nossas mentes sob pena de deturpá-los.

Antes da invenção da escrita, os ensinamentos eram transmitidos de forma oral, na qual obrigava a mente gravar certas informações. Após a criação da escrita, o conhecimento foi simbolizado (uma forma de ocultar tais conhecimentos quando posto nos papeis ou livros). Assim, o sentido dos termos supracitados resume-se em um conhecimento não simbolizado que deve ser vivido e difícil de ser traduzido.

Oposto ao dualismo moderno que separa a humanidade da natureza, a filosofia Ubuntu tem como objetivo o conhecimento ou sabedoria ecológica, holística, propondo-se a explorar a variedade de interrelações dos seres vivos com a natureza. Assim sendo, Ubuntu pretende aceitar relações de forma entrosada entre pessoas, animais, plantas, insetos, árvores, mundo natural e espiritual. 
Ubuntu, portanto, preza pelo equilíbrio ecológico, todos os seres vivos têm valor intrínseco, as plantas e árvores merecem respeito e empatia, a natureza implica compaixão, os mortos conectam-se aos vivos espiritualmente, a terra sendo um bem humanitário e não só, não pode ser apropriada, comercializada e explorada igual à produção industrial moderna capitalista. O conceito de Ubuntu é, por definição, Naturocêntrica e, portanto, pode colaborar indubitavelmente para lidar com a crise ecológica e os problemas ambientais da modernidade.

\section{A Concepção De Mundo Na Filosofia Ubuntu}

Não é fácil explicar e conceituar o mundo na visão Ubuntu. A explicação está muito mais na tradição viva e nas fontes orais dos povos africanos. O escritor malinês Amadou Hampâté Bâ reproduzindo o pensamento do sábio maliano Tierno Bokar diz que "a escrita é uma coisa, e o saber, outra. A escrita é a fotografia do saber, mas não o saber em si. O saber é tudo aquilo que nossos ancestrais vieram a conhecer e que se encontra latente em tudo o que nos transmitiram" (Bâ Hampâté, 2010, p. 167).

Nas comunidades africanas, as palavras carregam um valor moral fundamental porque estão ligadas a espiritualidade divina e forças ocultas. Com base na tradição oral a concepção de mundo na visão Ubuntu compreende a natureza e os seres que nela habitam (desde animais, insetos, plantas, árvores, pessoas, montanhas, pedras, mar, rios, lagoas, bem como os espíritos que fazem mover a própria natureza). Em vista disso, a filosofia Ubuntu concebe o mundo pela formação de dois elementos: físicos e espirituais. Os elementos físicos são normalmente decompostos ou repartidos em duas esferas de existência: céu e terra. A terra é o espaço de domínio da existência e vivência dos seres vivos (pessoas, animais, insetos, pássaros, rios, mares, montanhas, árvores, plantas, pedras, etc.). O céu é o lugar dominado por Nzambi na companhia dos espíritos divinos ancestrais ou Orixás. Nzambi e 
os espíritos da divindade são responsáveis pela modelagem dos seres e, encarregados pelo uso da sabedoria para a interpretação do passado, presente e futuro, assim como a organização geral da terra. Os espíritos da divindade ou Orixás também protegem os seres vivos contra as forças ou espíritos malignos. O professor moçambicano, atualmente vinculado à Universidade da Integração Internacional da Lusofonia Afro-Brasileira, Luís Tomás Domingos, explica essa cosmovisão africana da seguinte forma:

Expressando antropocentricamente, Zambi (Deus) é gerador e mentenedor do Homem. A sabedoria Africana sobre Deus é expressa nos provérbios, nas canções, orações, nomes, mitos, histórias, ritos, rituais e nas diversas dimensões das cerimônias religiosas. Bazimus, os espíritos, explicam o destino do homem; o homem é o centro dessa ontologia; animais, vegetais e fenômenos naturais e objetos sem a vida biológica constituem o meio ambiente onde o homem vive, se aprovisiona, extrai os meios de existência e, se for necessário, o homem estabelece relações mística com ele. Esta ontologia antropocêntrica é uma unidade completa. É uma relação de solidariedade na qual não pode haver ruptura ou destruição. E se acontecer o contrário, causa desequilíbrio do próprio homem, da natureza, enfim, de todo o Universo. Destruir ou remover uma destas categorias é destruir toda a existência incluindo a destruição do Criador. A soma desses elementos constitui uma força, poder, energia que penetra em todo o Universo. É Deus a Fonte Controladora desta força, mas os espíritos tem acesso a uma parte dela. (Domingos, 2011, p. 3-4).

Os ancestrais também habitam o céu na companhia de Nzambi, pois na cultura africana, os mais velhos/adultos após a morte tornam-se ancestrais e pequenas divindades em suas comunidades. A morte é observada como uma forma de renovação e transição dos seres humanos de um nível de existência, na terra, para outro nível, no céu. Deste modo, quando uma pessoa transita de um nível 
para o outro (da terra para o céu), imediatamente obtém grande poder e autoridade e, se torna uma divindade para a sua própria família ou linhagem. Para além de possuírem uma relação íntima com os seres humanos, os ancestrais protegem o seu povo e agem como intermediários entre os vivos, mortos e os espíritos divinos. Por isso, todos os ancestrais merecem respeito. Um ancestral é dotado de conhecimento e sabedoria enquanto vivo, apenas os adultos têm esta proeza.

A concepção Ubuntu acredita que a personalidade humana tem dois elementos principais: físico e espiritual. O elemento físico é coletivamente conhecido como corpo, à parte espiritual é designada como alma. O elemento mais importante da parte física é o coração, além de desempenhar uma função que estabelece ou conecta a parte espiritual (alma) com a carnal (física). Quando um homem morre, seu espirito permanece vivo, em seguida, vai para o céu como um corpo novo. A existência da humanidade na cosmovisão Ubuntu é determinada pelo Universo, sendo este movido pela ordem dos seres na natureza. Entretanto, existe e sempre existiu uma conexão natural entre o homem e a natureza. Infelizmente esta relação foi se perdendo com a construção da sociedade moderna baseada na concepção ocidental. A esse respeito, o professor Domingos, situa as diferenças entre a arte de viver dos Ocidentais, europeus e a arte de viver dos Africanos:

Para o ocidental, de uma maneira geral, o projeto maior da vida é dominar e transformar a natureza e obter o proveito, o capital, o poder econômico à todo custo. E o objetivo desse esforço nesta lógica utilitarista é, muitas vezes, para impor e ostentar o seu "status social" na sociedade, mesmo sem os meios técnicos necessários, mas sempre com a arte de vencer sem ter a razão. Enquanto na concepção tradicional africana, o projeto maior da vida do homem é encontrar o equilíbrio, a harmonia entre o homem e a natureza no Universo. Mesmo engajado na obra moderna de transformação, sempre guarda certa docilidade profunda com a natureza. Trata-se de uma dimensão relacional 
de homem/natureza na sua individualidade e coletividade integrada. (Domingos, 2011, p. 2).

A modernidade propõe e pratica a separação do ser humano da natureza, assim como implanta a supremacia da humanidade sobre os restantes elementos componentes da própria natureza. Percebe-se que, na visão Ocidental, o ser humano observa a natureza como parte externa e que deve e pode explorá-la para a satisfação dos seus caprichos sem importar os danos que nela infringe. A concepção Ocidental fomenta a disputa humana por espaço na terra, isolando-se, deste modo do seu gênesis para a criação e construção das cidades. Neste mundo, a beleza animal deve ser enjaulada para facilitar a visitação segura da curiosidade humana (Souza Filho, 2015). Tudo aquilo que se considera diferente torna-se atrativo de diversão ou deleite humano.

O passado recente concernente à invasão do mundo Ocidental ao mundo africano foi desalmado e cruel. Quando os europeus chegaram à África, encontraram uma realidade diferente, cultura e hábitos não vistos antes por eles, o que os levou a designarem os africanos como primatas, atrasados, não civilizados ou povos das florestas, sem alma e sem fé. Inclusive, alguns africanos eram capturados, enjaulados e levados para exposição nas praças europeias como atração circense. Exemplo disso foi o conhecido caso de Sarah Baartman, uma mulher negra Sul-africana de origem Khoisan, que foi retirada de sua terra para ser exibida na Europa, especialmente no Reino Unido, no século XIX, como animal exótico e aberração. Milhares de pessoas pagaram para admirar e tocar partes de seu corpo de dimensões fora do padrão europeu. Sarah foi apenas um caso entre centenas de milhares de abusos cometidos pelo povo europeu contra a cultura e os povos africanos. À vista disso, os Bantu passaram a conceber o mundo Ocidental como dotado de certa imaturidade espiritual, ou seja, as pessoas não crescem espiritualmente e por isso são caracterizados como violentos. A ideia Ocidental de que a natureza seria uma máquina morta a ser explorada para o benefício próprio agride a concepção africana de mundo e sua perspectiva humana, por isso, neste sen- 
tido, os africanos se consideravam muito mais humanos e avançados espiritualmente que os europeus. Na perspectiva Ubuntu, a meta humana é atingir o equilíbrio para gerar harmonia. Enquanto que na concepção ocidental, o objetivo é a dominação e a exploração para alcançar a supremacia e poder. Não existe uma relação de intimidade entre a sociedade humana ocidental e a natureza, como na concepção Ubuntu.

Com base na espiritualidade, os Bantu entendem que o europeu é caracterizado como um ser violento, e essa violência, está determinada pelo espaço territorial e geográfico onde sofreu a sua evolução, porque evolui num mundo de escassez, na qual teve de emigrar e matar para sobreviver e encontrar melhores condições de vida. Por conviver em um universo com poucas alternativas, tornou-se um predador, e quanto mais mata, mais se desumaniza. O ambiente em que se processou a evolução do europeu foi hostil, e, consequentemente, proporcionou e condicionou a psique do povo ocidental. Por isso, os colonizadores ao chegarem à África e as Américas ficaram perplexos ao se depararem com a biodiversidade e as riquezas naturais dessas regiões, repletas de alimentos naturais ou transformados pelos humanos locais. Isso porque, o continente europeu nunca foi rico em fauna e flora na mesma proporção que África ou América, por isso, o ocidente não manteve contato com a natureza do mesmo jeito que os tradicionais africanos e americanos tiveram. Por esta razão, o homem europeu entende-se como elemento fora da natureza, e quando chega à floresta a destrói e usa os animais como caça desportiva. Esse espírito agressivo do povo europeu centrado no sexo masculino é explicado pelo historiador, antropólogo, físico e político senegalês Cheikh Anta Diop ${ }^{10}$ (1974) com a teoria do berço, na qual destaca o conflito existente entre duas culturas: europeia e africana.

Para os povos africanos, a natureza está legitimamente viva e cada entidade dentro dela está provida de sabedoria e conhecimento. Deste modo, as pedras são vistas como anciãs da terra, as montanhas são residências de seres poderosos, as florestas são

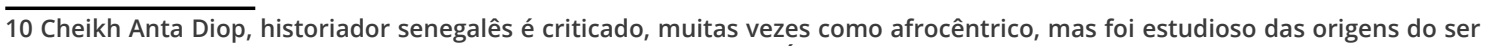
humano e faz crítica ácida à violência do colonialismo europeu na África. 
entidades vivas, a terra é a fonte da vida, os animais são seres especiais e míticos que na companhia dos ancestrais transmitem sabedoria e representam a vivacidade, a vegetação é o princípio das árvores da vida, fecundidade e proteção. Nessa perspectiva, Professor Luíz Tomás Domingos descreve:

O universo no qual vive e morre o Africano se compõe de dois espaços ou modos distintos. Um escondido e invisível: é o mundo de todos os seres invisíveis, espirituais; outro visível e observável: o mundo dos homens, dos animais, dos vegetais e de todo reino mineral. Certos animais são totens, muitas vezes, para uma determinada família. Uma relação que se explica pela fraternidade e primogenitura do animal, ou pela associação dos animais míticos com os primeiros homens aos quais teriam transmitido à sabedoria. Na vegetação, conforme a visão do mundo Africano, se encontra o principio das árvores da vida, da fecundidade e da proteção. E nas grandes horas de existência, os homens da religião tradicional africana respeitam profundamente a natureza. Eles se dirigem às florestas sagradas para realizar os ritos de passagem, de iniciação, etc. As mulheres se aproximam destas florestas, das ervas, das plantas para efetivar a sua maternidade. E há uma relação particular dos homens com os minerais; pedras que possuem potenciais especiais. (Domingos, 2011, p. 7).

Desde antiguidade os povos africanos interagem com animais, plantas, rochas, montanhas, terra, rios, mar etc., deste modo, na relação entre o ser humano e a natureza, a pessoa não é um sujeito abstrato, separado, independente das condições ecológicas da sua existência. "O individuo não está separado das condições genealógicas e de seus pressupostos míticos, místicos, mágicos ou religiosos da terra" (Domingos, 2011, p. 8). Se existe a humanidade é porque existiram os nossos ancestrais e, as memórias dos nossos antepassados estão dentro de nós. O que os nossos antepassados foram é o que somos hoje. Nós somos a continuidade dos nossos ancestrais, deste modo, a ancestralidade é um registro genético e espiritual. 
Relativamente à relação das gentes com a terra, o mundo africano estabelece um ritual de aliança com os espíritos divinos, ancestrais ou Orixás, antes do ser humano usá-la. Por ser a fonte da vida, a terra não pode ser usada sem uma previa mediação de Nzambi e os Orixás. Muito antes de ser um espaço ocupado por alguns seres da natureza, a terra é uma entidade espiritual na qual se origina a fonte da vida. O padre capuchino Adalberto de Postiona que viveu longos anos no Congo entendeu essa relação:

Esta docilidade fraternal aos ritmos da natureza é um dos aspectos mais originais da cultura Africana. Nesta atitude respeitosa para com a natureza se encontra um conjunto de valores positivos: a confiança na natureza infra-humana; a certeza pacifica de quem vivendo em harmonia com sua sábia conselheira, poderá usufruir das riquezas e repousar em seu doce ritmo; a primazia dos valores da natureza sobre os da técnica; a superioridade da fecundidade espontânea da natureza sobre as produções e técnicas artificiais; a estima da humilde comunhão com a vida, respeitada em seu profundo mistério (Postiona, 1968, p. 29-30).

Na cosmovisão africana humaniza-se o que a modernidade denomina por botânica por intermédio da percepção ecológica e dos ciclos cósmicos reverenciando a vida em todas suas proporções e profundidades (Fortunato, 2019).

\section{A Metafísica Da Filosofia Ubuntu}

O mundo africano não é somente material, existe uma multi-espiritualidade respeitada pelos povos que une o continente como um todo. Tudo que se encontra na dimensão física encontra-se na dimensão metafísica. Ao contrário do que se pensa, a espiritualidade nunca foi uma religião, porque é uma forma sofisticada de ciência que os povos tradicionais africanos ou os ancestrais usam para interpretar o Universo, seus mistérios e suas manifestações 
Ubuntu: uma filosofia alternativa à crise ambiental

Carlos Frederico Mares De Souza Filho • Nicolle Sayuri Uyetaque • Hermelindo Chico

cósmicas. Uma das funções da filosofia Ubuntu é a compreensão ou entendimento do ser. O entendimento Ubuntu do ser envolve três níveis de existência humana, que pode ser designada por estrutura onto-triádica de ser.

Uma vez que dois destes níveis referem-se a seres que são desconhecidos ou invisíveis, podemos nos referir a eles como a ontologia dos seres invisíveis. A ontologia de seres invisíveis é o discurso sobre o desconhecido a partir da perspectiva dos vivos. O desconhecido permanece desconhecido do lado dos vivos. No entanto, é crível e por causa dessa crença que tem uma influência direta na vida dos vivos. Neste sentido, a crença no desconhecido desconhecível é metafísica. É uma afirmação, baseada em crença, ao conhecimento sobre os seres fora do domínio do mundo dos vivos. A ontologia de seres invisíveis, portanto, a base da metafísica Ubuntu (Ramose, 1999, p. 11).

\section{O autor continua:}

De acordo com o entendimento Ubuntu de ser, o mundo da metafísica é o mundo dos u-nkulu-nkulu: a grandiosidade do grande; o inefável. O inefável não é nem macho nem fêmea. Mas pode ser generalizado em todo caso como uma fêmea-macho (hermafrodita) de acordo com a lógica $u$ - (línguas Nguni) ou mo- (Línguas Soto). O ponto principal é que u-nkulu-nkulu não é definível nem descritível. Portanto, é melhor ficar calado sobre o desconhecido e simplesmente reconhecer a inefabilidade do mo-dimo (unkulunkulu ${ }^{11}$ ). Isto é colocado como um ponto de partida fundamental para explicar o porquê à espiritualidade e a filosofia Ubuntu não possuem nenhuma teologia (Ramose, 1999, p. 11).

\footnotetext{
11 Unkulunkulu na Língua Zulu do povo da África do Sul, assim como Nzambi na expressão da Língua Kimbundo de Angola, é o Criador ou Criadora Suprema. Ela (e) criou tudo, da terra e da água ao homem e aos animais. Embora os termos não tenham uma tradução exata, para o português significaria "Deus todo-poderoso". Tantos os Zulus como os outros povos descendentes de Bantus, acreditam que Unkulunkulu ou Nzambi é uma força espiritual e imutável que rege todos os fenômenos da natureza.
} 
O Professor de filosofia do Triton College, USA, Leke Adeofe clarifica a concepção tripartida que caracteriza o sistema de pensamento africano da seguinte forma:

\begin{abstract}
Uma pessoa é compreendida como sendo seu ou sua ara (corpo), emi (mente/alma) e ori ("cabeça interior"). Diferente de ara, que é física, quanto emi quanto ori são mentais (ou espirituais). Esta dicotomia pode nos induzir a pensar a visão africana como dualista. Mas seria um erro pensar assim, já que o ori é ontologicamente concebido independente dos outros dois elementos. Portanto, a visão africana é propriamente pensada como triádica. É filosoficamente interessante que uma pessoa seja a criação de diferentes divindades. Ara, o corpo, é construído por Orisa-nla, a arqui-divindade. Olodumare (Deus ou “Divindade Suprema") gera o emi; enquanto que outra divindade, Ajala, é responsável por criar o ori. Ara, é entidade corporal da cabeça ao pé, incluindo os órgãos internos e externos, e se torna consciente com o emi que, separada desta capacidade de dar vida, é compreendida como imortal e transmigratória. A cabeça interior ou metafísica, ori, a outra entidade não-corpórea, é o portador do destino e, portanto, constitutivo da personalidade. (Adeofe, 2004, p. 1-2).
\end{abstract}

Assim sendo, dentro do limite da metafísica africana, uma pessoa é feita de três elementos, ara, emi e ori. Desde que suas ontologias sejam logicamente independentes uma da outra, os três elementos são ontologicamente distintos e propriamente concebidos como uma visão triádica de pessoa. A visão africana é rigorosamente pensada como triádica. O pensamento dos povos africanos caracteriza-se pela concepção tripartida. Uma pessoa é compreendida como um ser carnal (corpo) e espiritual (mente e alma). Deste modo, o ser humano compreende o corpo, a mente e a alma. O corpo representa a parte física, enquanto a mente e alma formam a parte espiritual. Seria equívoco pensarmos a visão africana como dualista, já que a alma é ontologicamente engendrada 
independentemente do corpo e da mente. Assim sendo, dentro de uma perspectiva da metafisica Ubuntu, o ser humano é feito de corpo, mente e alma. As três dimensões são ontologicamente e exatamente idealizadas como uma visão triádica de pessoa. A presença da alma no corpo humano é tida como uma consciência fenomênica, isto é, um efeito da respiração divina que se manifesta no corpo. A mente é considerada importante para o exercício cognitivo ou racional humano.

Alguns filósofos africanos, como M.A. Makinde, entendem que a atividade raciocinativa dos povos africanos é diferente de uma pessoa como em certas tradições ocidentais, como por exemplo, a cartesiana.

\begin{abstract}
Em verdade, a visão ocidental para qual onde está a alma, está à pessoa, oposto a visão africana. Alguns filósofos africanos, no entanto, têm descrito a alma como "a mais duradoura e a mais importante característica de uma pessoa", mas não há suporte dentro do sistema de pensamento africano para compreender isto em um sentido platônico ou cartesiano. Que a mente/alma seja considerada a mais duradoura característica pode tentar-nos a pensar que, para os africanos, a presença da mente e a alma corporiza a pessoalidade de forma muito semelhante a sistemas de pensamento ocidentais. Mas deve-se resistir a esta tentação já que eles também alegam que a mente/alma não possuem qualidades variáveis, ou seja, a mente/alma não possuem características distintivas (Makind, 1985, p. 195-197).
\end{abstract}

Uma questão filosoficamente interessante, é que na componente metafisica, a expressão verbal possui maior impacto do que a comunicação escrita. À vista disso, a principal característica de uma pessoa africana é a fala ou a voz. Por meio da fala emitimos e produzimos sons com as cordas vocais que usamos para a comunicação com os humanos, animais, vegetais, montanhas, assim como para ativação de alguns poderes espirituais pela invocação dos nomes ancestrais. Por esta razão, os nomes em África, possuem um significado e respeito grande. Assim, uma pessoa afri- 
cana quando altera ou desrespeita o seu nome, perde a linhagem espiritual com a sua ancestralidade e cultura. O nome caracteriza uma pessoa como ser pertencente de uma dada cultura. Quando uma pessoa nega o seu nome, automaticamente, perde o seu poder e a proteção ancestral. Assim, o nome é o veículo espiritual do individuo. A espiritualidade é um elemento muito ligado à realidade dos povos africanos. A adoção de nomes estrangeiros significa a morte da espiritualidade e o código na perspectiva onomástica. Os principais elementos da cultura africana correspondem ao nome, à língua e a tradição. A língua é o meio onde o nome e a tradição se manifestam.

No livro "1942: o encobrimento do outro" (a origem do mito da modernidade), o filósofo argentino Enrique Dussel cita o filósofo europeu Hegel, que sem conseguir entender o mundo e a cultura africana, o interpretou da seguinte maneira:

Esse modo de ser dos africanos explica o fato de eles serem tão extraordinariamente facilmente fanatizados. O Reino do Espirito entre eles é tão pobre e o Espirito tão intenso que basta uma representação que lhes é inculcada para levá-los a não respeitar nada, a destroçar tudo [...] A África [...] não tem propriamente história. Por isso, abandonamos a África para não mencioná-la mais. Não é uma parte do mundo histórico; não representa um movimento nem um desenvolvimento histórico [...] O que entendemos propriamente por África é algo isolado e sem história, sumido ainda por completo no espirito natural, é que só pode ser mencionado aqui, no umbral da história universal. (Hegel, 1945 apud Dussel, 1993, p. 20).

O pensamento do Hegel exprime a profunda ignorância dos europeus na interpretação do universo metafisico e espiritual africano. Além dos insultos e desrespeito de Hegel sobre o modo de ser dos africanos, outros pensadores ocidentais designaram bruxaria e feitiçaria para descrever e interpretar o mundo africano. Seria errado descrevermos o universo africano desta maneira. 
Em África, nunca existiu bruxaria, feitiçaria ou magia negra, tais termos foram cunhados pelos invasores europeus para descrever a realidade africana. Os europeus não conseguiram compreender que a visão de mundo é relativo de acordo as culturas de cada povo. Cada cultura é responsável pela humanização de seu povo.

O pesquisador angolano Isidro Fortunato (2019) nos ensina que o encanto do universo africano está na sua espiritualidade que age como elemento de inclusão para o sustento da ordem e do equilíbrio social das comunidades. A visão de mundo em África não é antropocêntrica, mas sim Naturocêntrica, ou seja, ela funciona como um sofisticado e complexo ecossistema, reconhecendo o homem como elemento de um todo na equação cósmica. Exatamente o contrário acontece na visão de mundo europeia, que desloca o ser humano da sua natural mundivivência, definindo a racionalidade como elemento primordial para justificar a dominação sobre todos os demais elementos do ecossistema, sobre a natureza de é feito. Esse poder racionalista baseado na exteriorização do ego é a base do capitalismo, racismo, colonialismo, assim como de todas as demais formas de violência que determinam a presença do colonialismo europeu moderno no mundo.

O pensamento e a cultua africana são potentes e presentes no mundo atual. Também assim é o pensamento e cultura dos diversos povos da América, cuja cultura se aproximam da cultura africana, bastando, para isso ler o emblemático livro de Davi Kopenawa, um xamã Yanomami, da Amazônia que escreveu o desencanto com as culturas "brancas" modernas e sua ignorância em relação às forças da natureza. "A queda do céu".

\section{Considerações}

Nos últimos anos, a modernidade vem enfrentando inúmeros problemas de caráter ecológico e ambiental. A esse respeito, o professor da Universidade Stellenbosch da África do Sul, Lesley Le 
Grange (2015) considera que respostas a essas questões requerem rever completamente os conceitos e ideias que criaram os problemas, assim como doutrinas e padrões que formaram tais conceitos. "O estado atual do planeta levanta uma questão chave: como nós devemos viver de modo a garantir um futuro sustentável?" A questão não depende apenas de respostas individuais, mas um esforço coletivo de comunidades locais, Estados-nações e da comunidade global inteira. As respostas para a crise ecológica global não podem se basear na racionalidade que ceiou e agravou o problema, mas sim em respostas que contraponham tal racionalidade. Com isso, algumas alternativas vão surgindo de modo que se pense ou busque novas formas de racionalidade. Um exemplo disso é a filosofia africana Ubuntu proposta neste estudo, jungtamente com outros pensamentos de povos que se mantém íntimos da natureza.

A filosofia Ubuntu propõe uma racionalidade humana coletiva e relação dos seres com a natureza, mantido pela harmonia e equilíbrio para a ascensão da plenitude. Assim, Ubuntu é a base para a existência e manutenção de estruturas sócias igualitárias que é, de fato, uma característica necessária para as sociedades humanas modernas. Uma estrutura social igualitária sem a supremacia de gênero, sexo e raça como ordem, é o caminho para fortalecer e potencializar concepções de que a existência humana é uma condição coletiva e que deve ser preservada para continuidade da nossa sobrevivência. Assim, a estrutura social proposta por Ubuntu permite uma forma de organização, na qual as concepções políticas governamentais são influenciadas pelo modo de vida dos seres como um todo, que de tal forma procuram manter o equilíbrio com a própria natureza. Em vários países africanos, a filosofia Ubuntu tem sido incorporada nas políticas governamentais, especialmente educacionais, agrárias e culturais, servindo de base e estrutura para responder os problemas insurgentes. Essas organizações sociais organizadas em estados em África têm muita dificuldade de incorporar as concepções tradicionais dos povos porque são herdeiros, ainda, do colonialismo moderno, mas os 
próprios povos vão moldando ou têm que moldar os novos estados no sentido de romper com o colonialismo e criar um mundo novo em que todos, gentes ou não possam viver. Este é também um fenômeno que ocorre na América Latina onde concepções próximas ao Ubuntu se mantêm vivas e buscando espaço de realização.

Ubuntu apresenta uma concepção Naturocêntrica que age como um aprimorado e complexo ecossistema, corroborando o ser humano como parte integrante de um todo na equação cósmica. Ademais, Ubuntu tem como objetivo o conhecimento ou sabedoria ecológica, propondo-se explorar a variedade de interrelações dos seres vivos com a natureza. Assim, Ubuntu propõe relações entrosadas entre pessoas, animais, plantas, insetos, árvores, montanhas, mundo natural e espiritual. É nesse contexto que fundamenta-se a sabedoria e conhecimento do povo tradicional africano que consiste na natureza dos seres, principalmente o principio básico que os ordena. Um dos sentidos profundos dos povos Africanos tradicionais é manter a natureza como um espaço de moradia humana e de cultura, para conviver de maneira aceitável, harmoniosa e equilibrada. A universalidade do Ubuntu está no fato de propor harmonia assim como as culturas do bem viver na América Latina.

\section{Referências}

ADEOFE, Leke. 2004. Personal Identity in African Metaphysics. In: BROWN, Lee (ed.) African Philosophy. New and Traditional Perspectives. New York: Oxford UP, pp. 69-86. Tradução para uso didático de: Benilson Souza Nunes.

Bâ, A. Hampaté. 2010. A tradição viva. In: KI-ZERBO, Joseph. História geral da África, I: Metodologia e pré-história da África. 2. ed. rev. - Brasília: UNESCO, 2010, pp. 167-212 
BECK, Ulrich, 2012. A reinvenção da política: rumo a uma teoria da modernidade reflexiva. In: GIDDENS, Anthony; LASH, Scott; BECK, Ulrich. (orgs.). Modernização Reflexiva: política, tradição estética na ordem social moderna. São Paulo: UNESP, 2012, p.11-15.

CUNHA JÚNIOR, Henrique. 2010. NTU. Revista Espaço Acadêmico, Maringá, n. 108. p. 81-92. Disponível em: <http://periodicos.uem. br/ojs/index.php/EspacoAcademico/article/viewFile/9385/5601>. Acesso em: 10 ago. 2019.

CHICO, Hermelindo Silvano; UYETAQUI, Nicolle Sayuri França. 2019. As contribuições da filosofia africana Ubuntu para os 17 objetivos de desenvolvimento sustentável da Agenda 2030 das Nações Unidas. In: TREVISAN, N. Marie; SALLES, Letícia M. Rutkowski (orgs.). A construção de um pensamento: 20 anos do NEADI-PUCPR. Curitiba: Instituto Memória. Centro de Estudos da Contemporaneidade, 2019, p. 244-246.

Diop, Cheikh Anta. 1974. The African origin of civilization: Myth or reality? (M. Cook, Trans.). New York: Lawrence Hill. (Original work published 1955). Disponivel em: <https://www2.unifap.br/ neab/files/2018/05/Dr.-Cheikh-Anta-Diop-A-Origem-Africana-daCiviliza\%C3\%A7\%C3\%A3o-ptbr-completo.pdf>. Acesso em: 10 set. 2019.

DOMINGOS, Luís Tomás. 2011. A visão africana em relação à natureza. ANAIS DO III ENCONTRO NACIONAL DO GT HISTÓRIA DAS RELIGIÕES E DAS RELIGIOSIDADES - ANPUH - Questões teórico-metodológicas no estudo das religiões e religiosidades. In: Revista Brasileira de História das Religiões. Maringá (PR) v. III, n.9, jan. Disponível em http://www.dhi.uem.br/gtreligiao/pub.htm. Acesso em: 24 ago. 2019.

DUSSEL, Enrique. 1993. 1492: o encontro do outro (a origem do mito da modernidade). Tradução. Jaime A. Clasen. Petrópolis: Vozes, p. 20. 
FORTUNATO, Isidro. 2019. O perigo do capitalismo "Africano". Luanda 10/10, 2019. Facebook: Isidro Fortunato Fortunato. Disponível em: <https://www.facebook.com/photo.php?fbi$d=2094709344169260 \&$ set $=p .2094709344169260 \&$ type $=1>$. Acesso em: 15 out. 2019.

KAGAME, Alexis. 1956. La philosophie Bantu-Rwandaise de I'Etre. Bruxelas: ARSC, p. 449-454.

KAPHAGAWANI, Didier N; MALHERBE, Jeanette G. 2002. African epistemology. In: COETZEE, Peter H.; ROUX, Abraham P.J. (eds). The African Philosophy Reader. New York: Routledge, 2002, p. 219-229. Tradução para uso didático por Marcos Rodrigues. Disponível em: <https://docero.com.br/doc/1e885v>. Acesso em 04 jun. 2019.

KOPENAWA, Davi; BRUCE, Albert. 2015. (orgs.) A queda do céu: Palavras de um xamã yanomami. tradução Beatriz PerroneMoisés; prefácio de Eduardo Viveiros de Castro - 1a ed. - São Paulo : Companhia das Letras.

LE GRANGE, Lesley. 2015. Ubuntu/Botho como uma ecofilosofia e ecosofia. Tradução para uso didático de LE GRANGE, Lesley. Ubuntu/Botho as Ecophilosophy and Ecosophy. Journal of Human Ecology, 2015, p. 301-308, por Leonardo da Silva Barbosa. Disponível em: <http://docplayer.com.br/73578789-Ubuntu-botho-como-uma-ecofilosofia-e-ecosofia.html>. Acesso em: 01 de jun. 2019.

\section{MAKINDE, M. A. 1985. An African Concept of Human}

Personality: The Yoruba Example. Ultimate Reality and Meaning 7.3, p. 195.

MORIN, Edgar; KERN, Anne Brigitte. 2003. (orgs.) Capítulos 1, 2 e 3. In: Terra-Pátria. Porto Alegre: Sulina.

MOTA, Susana Isabel. 2010. Maat: A expressão de todo o mundo egípcio numa só palavra. Revista História e-história, Abril, p. 1-21. Disponível em: <https://www.researchgate.net/profile/ 
Susana_Mota/publication/276937173_Maat_A_Expressao_do_ Mundo_Egipcio_numa_so_palavra_Maat_The_expression_of_the_ egyptian_world_in_one_word/links/555c68fd08ae8f66f3ae0b1d/ Maat-A-Expressao-do-Mundo-Egipcio-numa-so-palavra-Maat-Theexpression-of-the-egyptian-world-in-one-word.pdf>. Acesso em: 31 mar. 2020.

POSTIOMA, Adalberto de. 1968. Filosofia Africana. Luanada: Seminario de Luanda, p. 29-30.

RAMOSE, Mogobe B. 1999. African Philosophy through Ubuntu. Harare: Mond Books, p. 49-66. Tradução para uso didático por Arnaldo Vasconcellos. Disponível em: <https://filosofia-africana. weebly.com/uploads/1/3/2/1/13213792/texto16.pdf>. Acesso em 8 jun. 2019.

RAMOSE, Mogobe B. 2002. A ética do ubuntu. Tradução para uso didático de: RAMOSE, Mogobe B. The ethics of ubuntu. In: COETZEE, Peter H.; ROUX, Abraham P.J. (eds). The African Philosophy Reader. New York: Routledge, 2002, p. 324-330. Tradução de Éder Carvalho Wen. Disponível em: <https://filosofia-africana.weebly.com/uploads/1/3/2/1/13213792/mogobe_b._ramose_-_a_\%C3\%A9tica_do_ubuntu.pdf>. Acesso em: 24 jun. 2019.

SOUZA FILHO, Carlos Frederico Marés. 2015. De como a natureza foi expulsa da modernidade. Revista Crítica do Direito, n. 5, vol. 66, ago/dez. p. 88-106.

SHAVA S, ZAZU C, TIDBALL K, O'DONOGHUE R. 2009. Conhecimento local como fonte de resiliência comunitária. Indilinga: Revista Africana de Sistemas de Conhecimento Indígenas, vol 8, n², p. 218-229. Disponível em: <https://www. ajol.info/index.php/indilinga/article/view/116433>. Acesso em: 10 jun. 2019. 